\title{
Facilitative and inhibitory effects of location and frequency cues: Evidence of a modulation in perceptual sensitivity
}

\author{
TODD A. MONDOR \\ Mount Allison University, Sackville, New Brunswick, Canada \\ and \\ LYNN M. BREAU \\ Dalhousie University, Halifax, Nova Scotia, Canada
}

\begin{abstract}
The possibility that facilitative and inhibitory effects of auditory cues result because of a modulation in perceptual sensitivity was examined. Listeners were presented with a cue followed by a target, with the time period between the two varied at stimulus onset asynchronies (SOAs) of 150,450 , or $750 \mathrm{msec}$. In two conditions, the cue and target were either the same or different in location or frequency. In both conditions, listeners were required to identify the rise time of the target. Whereas the cue was presented in isolation, the target was presented in a wide-band noise background such that the required discrimination was made relatively difficult. In both conditions, a facilitative effect was apparent at the 150-msec SOA and an inhibitory effect was apparent at the 750-msec SOA for both accuracy and response time measures of performance. That these results were apparent for a judgment unrelated to the manipulated cue-target relation suggests strongly that both location-based and frequency-based auditory inhibition of return result primarily because of changes in perceptual sensitivity.
\end{abstract}

Many investigations of auditory selective attention have been founded on a priming paradigm wherein an advance cue is followed by a target to which a response is required. This research has established that, whether or not there is a predictive relation between cue and target, accurate advance information regarding target location or frequency facilitates performance (Creelman, 1959; Green, 1961; Mondor \& Bregman, 1994; Mondor \& Bryden, 1992; Mondor \& Zatorre, 1995; Moray, 1959, 1974; Rhodes, 1987; Scharf, Quigley, Aoki, Peachey, \& Reeves, 1987; Schlauch \& Hafter, 1991; Spence \& Driver, 1994, 1997; Treisman, 1960, 1969). Recent work has established that whereas at brief intervals between cue and target, performance is better for targets preceded by accurate cues (i.e., a facilitative effect), at more lengthy cue-target intervals, performance is better for targets preceded by inaccurate cues (i.e., an inhibitory effect-Mondor, Breau, \& Milliken, 1998; Reuter-Lorenz, Jha, \& Rosenquist, 1996; Schmidt, 1996). These effects do not appear to depend on general decision requirements, because Mondor, Breau, and Milliken reported a transition from facilitation to inhibition as a function of stimulus onset asynchrony (SOA) for both detection and discrimination tasks. This

This research was supported by grants from the Natural Sciences and Engineering Research Council of Canada and the Heart and Stroke Foundation of New Brunswick to T.A.M. Correspondence should be addressed to T. A. Mondor, Department of Psychology, 49A York St., Mount Allison University, Sackville, NB E4L 1C7, Canada (e-mail: tmondor@mta.ca). performance pattern has been labeled inhibition of return (IOR) by those who have investigated it in the visual modality (e.g., Maylor \& Hockey, 1985; Posner \& Cohen, 1984; Rafal, Calabressi, Brennan, \& Sciolto, 1989; Tipper, Weaver, Jerreat, \& Burak, 1994).

Most investigators of visual IOR have assumed, either implicitly or explicitly, that facilitative and inhibitory effects reflect differential sensitivity to signals as a function of the distribution of attention (e.g., Downing, 1988; Posner \& Cohen, 1984; Tipper et al., 1994). However, other interpretations of the effects of visual cues on performance have been offered. Specifically, the possibility that response bias may play a role in engendering facilitative effects was proposed by Shaw $(1978,1984)$, who argued that the amount of evidence required in order to make a response may vary as a function of the spatial relation between cue and target. Similarly, Kinchla (1992) has argued that if the probability that the target is presented in the same location as that of the cue is greater than chance, then decision processes may account for the facilitative effect normally observed. "Suppose the quality of processing was the same in cued and noncued regions but the subject simply give more weight or credence to the information extracted from the cued region" (p. 730, italics in original). If this is the case, one might expect to observe enhanced performance for targets presented in cued locations simply because of a response bias. To address this possibility, several investigators set out to determine whether the distribution of visual attention primarily affects perceptual sensitivity ${ }^{1}$ or response 
biases. Whereas many of these studies have been criticized on methodological grounds (see Kinchla, 1992, for a discussion), on balance the evidence suggests that facilitative effects of visual spatial cues reflect both perceptual sensitivity and decision processes (Bashinski \& Bacharach, 1980; Downing, 1988; Hawkins et al., 1990; Klein \& Hansen, 1990; Müller \& Findlay, 1987; Müller \& Humphreys, 1991).

Other nonattentional interpretations of inhibitory effects in visual attention have also been offered. Harvey (1980; see also Bernstein, Chue, Briggs, \& Schurman, 1973; Nickerson, 1973; Sanders, 1975) reported the results of an experiment in which subjects were required to determine whether a category cue was followed by a "high" or "low" target. Both the cue and target could be either a high- or a low-pitched tone or one of two light bulbs arranged so that one was above the other. There was no predictive relation between the modality or category of the cue and that of the target, and SOAs were quite lengthy, ranging from 550 to $1,050 \mathrm{msec}$. Harvey found an inhibitory effect, in that targets were judged more slowly when they were of the same category as that of the cue than when they were different. Rather than interpreting this effect as caused by an attentional process, Harvey suggested that the slowing on "category repetition" trials arose because a response to the cue was inhibited. According to this proposal, when the target category matches that of the cue, response time (RT) is slowed because the necessary response has been inhibited (see also Klein \& Taylor, 1994, who argued that visual IOR may be more representative of response processes than of attention). The possibility that response inhibition might act as the principal cause of an inhibitory cuing effect would seem to be less likely when target detection or identification is required, because the response is independent of the properties of the cue. That inhibitory effects have recently been reported for such tasks (e.g., Lupiáñez, Milán, Tornay, Madrid, \& Tudela, 1997; Pratt, 1995; Pratt, Kingstone, \& Khoe, 1997) certainly suggests that response inhibition is not the primary determinant of the inhibitory component of visual covert orienting.

The accumulated evidence regarding the effects of visual spatial cues on performance might be summarized, then, as indicating that (1) the facilitative effect results because of both enhanced perceptual sensitivity for targets appearing in cued locations and response biases favoring cued locations, and (2) the inhibitory effect is not likely due to inhibition of a response to the cue. To our knowledge, no study has yet been designed to address the possibility that facilitative and inhibitory effects of auditory cues arise because of response biases. Although recent detection studies (Mondor, Breau, \& Milliken, 1998; ReuterLorenz et al., 1996; Schmidt, 1996) suggest strongly that inhibition of a response to the cue is not an important determinant of the inhibitory effect of auditory cues, alternative explanations that emphasize the role of response biases may not be so easily rejected. This may seem some- what counterintuitive, given that a two-alternative forced choice ( $2 \mathrm{AFC}$ ) paradigm has been used in previous studies of auditory IOR and these studies have yielded evidence of significant facilitative and inhibitory response time (RT) effects. However, although it has often been argued that accuracy may be fairly confidently interpreted as indicative of sensitivity in a $2 \mathrm{AFC}$ paradigm (e.g., Gescheider, 1985), this is not necessarily so. Indeed, when the response required of listeners (localization or frequency identification) is related to the manipulated cuetarget relation, a response bias could be responsible for cuing effects. To elaborate, if subjects hold a response bias that favors one condition over another (e.g., a bias in favor of targets sounding in cued locations), then a performance advantage would be created that is unrelated to attentional processes (see, e.g., Greenberg \& Larkin, 1968; Kinchla, 1992; Mondor \& Amirault, 1998; Mondor \& Bregman, 1994; Shaw, 1978, 1984). Both facilitative and inhibitory effects could be explained in this way if the direction of this bias varied with SOA. Importantly, such a strategy would not necessarily be expected to produce a speed-accuracy tradeoff with higher error rates in the faster conditions. Rather, an advantage in favor of a cued location or frequency could well be apparent for both RT and accuracy measures (Kinchla, 1992). While requiring a detection response rather than a localization or frequency identification judgment would eliminate any tendency to base a response on the features of the cue, as Kinchla pointed out "even if a cue doesn't indicate which response is more likely, it can indicate which areas of an array should be given more weight when the decision process involves a weighted integration of impressions" (p. 728). Thus, response biases, albeit of a somewhat different nature, could also account for auditory IOR when performance is measured using a target detection task.

In addition to the possibility of response biases affecting both RT and accuracy measures in the same way, a less refined bias that overemphasizes response speed and underemphasizes response accuracy could also account for the evidence of auditory IOR so far reported. As $\mathrm{Pa}-$ chella (1974) has argued, "small differences in error rate can lead to large differences in reaction time. This is particularly true for the range of high, overall accuracy $(90$ to $100 \%$ ) typically found in reaction time experiments. This means, of course, that what may look like relatively meaningless error differences might contaminate reaction time values extensively" (pp. 60-61). Most investigations of auditory covert orienting, and all of those in which inhibitory effects have been reported, have yielded few errors, and investigators have, therefore, confined their interpretations to variations in RT. Indeed, in their studies, neither Reuter-Lorenz et al. (1996) nor Schmidt (1996) reported error rates for individual conditions, presumably because errors were quite rare in the detection tasks that they used. Whereas Mondor, Breau, and Milliken (1998) did report this information, error rates were very low (less than $1 \%$ in all conditions) when detection 
was required and no statistically significant variation was apparent. Although listeners made more errors when target discrimination was required (average of about $3 \%$ ), Mondor, Breau, and Milliken identified only a statistically significant facilitative effect at the 150 -msec SOA. Thus, because of these negligible error rates it has been impossible to evaluate the consistency of RT and accuracy measures of performance.

We addressed the possibility that location-based and frequency-based auditory IOR might be produced by response biases in the present study by examining identification of target rise time as a function of the spatial or spectral relation between cue and target. Because the judgment required of listeners was independent of the manipulated cue-target relation, performance should be relatively unaffected by a tendency to respond either in a way consistent or in a way inconsistent with an advance cue or by giving more weight to information in one location or frequency region. In addition, the standard cue-target paradigm typically used in investigations of IOR was adapted to increase task difficulty, so that both accuracy and RT could be used as meaningful measures of performance. Each trial began with a cue followed by a target. However, whereas the cue was presented in isolation, the target was presented in a background of wide-band white noise.

Different groups of listeners performed a target rise time identification judgment under conditions in which either the location or the frequency relation between the cue and target was varied. For both conditions, a pure tone cue was followed by a pure tone target. In the location condition, a target of the same frequency as that of the cue sounded from either the same location as that of the cue(a repeat trial) or the other location (a change trial). The target was embedded in a background of white noise, and a white noise distractor of the same subjective loudness was presented from the second location. In the frequency condition, the target, which was embedded in a background of white noise, sounded from the same location as the cue's but could be of either the same (a repeat trial) or a different (a change trial) frequency. If the facilitative and inhibitory effects on RT of location and frequency cues that have been reported recently are the result of changes in perceptual sensitivity, we should replicate this pattern of performance by using a target judgment that is independent of the manipulated cuetarget relation. In contrast, if auditory cuing effects result because of response biases, we should either fail to find evidence of facilitation and inhibition, or observe evidence of speed-accuracy tradeoffs with contradictory $\mathrm{RT}$ and accuracy effects.

\section{METHOD}

\section{Subjects}

Thirty-six undergraduate students attending Mount Allison University volunteered to participate in the experiment in exchange for course credit. None of the volunteers reported any corrected or uncorrected hearing problems. Different groups of 18 listeners participated in the location and frequency conditions.

\section{Materials}

Computer and sound system. A 486/50 IBM-compatible computer running the Maple programming environment (Bregman, Achim, \& Ahad, 1992) was used to present sounds and to record responses. Sounds were presented over Sony SRS-PC30 speakers located $45^{\circ}$ to the left, $45^{\circ}$ to the right, and directly in front of the listener.

Sounds. All sounds were synthesized at $32000 \mathrm{~Hz}$, using MITSYN (Henke, 1992). Ten cues, five of $500 \mathrm{~Hz}$ and five of $713 \mathrm{~Hz}$, were synthesized (these frequencies were chosen arbitrarily, with the constraint that they not be harmonically related). The five cues of each frequency differed in rise time (the speed with which maximal amplitude was obtained) with linear onset times of $5,15,25,35$, and $45 \mathrm{msec}$ and linear offset times of $45,35,25,15$, and $5 \mathrm{msec}$, respectively. Four targets, two of $500 \mathrm{~Hz}$ and two of $713 \mathrm{~Hz}$, were also created. Each target consisted of a pure tone embedded in a background of wide-band white noise $(0-10000 \mathrm{~Hz})$. The pure tone component of the two targets for each frequency differed in onset and offset time, with one having an onset time of $5 \mathrm{msec}$ and an offset time of $95 \mathrm{msec}$, and the other having an onset time of $95 \mathrm{msec}$ and an offset time of $5 \mathrm{msec}$. Whereas targets with 5-msec onset times sound "sharp," those with slow onset times sound "dull" (a similar task was used by Mondor, Zatorre, \& Terrio, 1998). Finally, for the localization task only, a distractor that consisted of the same wide-band white noise as that which constituted the background of the target sounds was synthesized. Whereas cues were $50 \mathrm{msec}$ in duration, targets were $100 \mathrm{msec}$ in duration. The subjective intensities of the cue, the target in the noise background (hereinafter referred to as the target), and the noise background alone (hereinafter referred to as the distractor) were all equalized subjectively at approximately $65 \mathrm{~dB}$.

\section{Design and Procedure}

Each trial consisted of the presentation of a cue, followed by a target. The cue-target SOA was randomly varied at 150,450 , and $750 \mathrm{msec}$. The cue and target were the identical in the manipulated feature (location or frequency) on $50 \%$ of the trials (i.e., repeat trials) and different on $50 \%$ of the trials (i.e., change trials). In different conditions, either the location relation or the frequency relation between cue and target was manipulated. In the location condition, the cue and the target could sound from either the left or the right speaker, and a distractor always sounded from the alternative location. The target and the distractor were presented simultaneously. In the frequency condition, whereas the cue and target always sounded from the same location (directly in front of the listener), their frequencies could be either the same or different. As for the location task, the cue consisted of an isolated pure tone, and the target consisted of a pure tone embedded in noise. In both the location and the frequency conditions, listeners were required to identify the rise time (fast or slow) of the target by pressing the " 1 " key if it had a fast onset time, and the " 0 " key if it had a slow onset time (this mapping was reversed for half of the subjects). The rise time of the cue was randomly varied $(5,15,25,35$, and $45 \mathrm{msec})$ in order to discourage listeners from using the rise time of the cue as a ruler with which to judge the rise time of the target (see also Mondor \& Bregman, 1994; Mondor, Zatorre, \& Terrio, 1998, where a similar logic was used). The duration difference between cues and targets was instituted for the same reason. The experiment was self-paced, so that subjects initiated each trial by pressing a key on a computer keyboard. The subsequent trial began $750 \mathrm{msec}$ following this initiating keypress.

Before completing any practice or experimental trials, an adaptive staircase procedure was used to calibrate for each listener the relative intensities of the tone and noise components of the target so as to yield a mean accuracy level of approximately $65 \%-70 \%$. The trials that constituted this calibration session functioned as the practice trials. No listener completed fewer than 48 , or more than 96 , cal- 
ibration trials. Following this calibration procedure, listeners completed 288 experimental trials ( 48 for each combination of repetition [repeat, change] and SOA [150,450,750 $\mathrm{msec}])$. Different groups of listeners participated in the location and frequency conditions. Accuracy feedback was provided following all practice trials, and feedback regarding percent correct was provided halfway through the experimental trials. Responses made prior to the presentation of the target, which were excluded from all calculations, accounted for less than 1\% of responses. Analysis of RTs was based on correct responses only. In addition, positive RTs more than 2.5 standard deviations faster or slower than the mean for each condition were excluded. Such outliers accounted for less than $2 \%$ of responses.

\section{RESULTS AND DISCUSSION}

Mean RT and percent errors for all conditions in the experiment are described in Table 1. For both location and frequency conditions, separate two-way withinsubjects analyses of variance (ANOVAs) (SOA [150, $450,750 \mathrm{msec}$ ] $\times$ repetition [repeat, change]) were performed using RT and percent errors as dependent variables. For simplicity, and because of the theoretical importance of examining facilitative and inhibitory effects for both conditions, the results for the location and for the frequency conditions will be discussed separately, followed by a formal comparison of performance in the two conditions.

\section{Location Condition}

Examination of the RT data revealed a significant main effect of SOA $[F(2,34)=14.73, p<.001]$, but not of repetition $(F<1)$. Critically, however, the SOA $\times$ repetition interaction also attained significance $[F(2,34)=8.21$, $p<.01]$. Planned comparisons verified the presence of a significant facilitative effect (i.e., an advantage for repeat over change trials) at the 150 -msec SOA and a significant inhibitory effect (i.e., an advantage for change over repeat trials) at the 750 -msec SOA ( $p<.05$ for both comparisons). The advantage for change trials at the 450-msec SOA approached significance $(p=.12)$.

Similar results were apparent for a parallel analysis of the error data. Whereas the main effect of SOA was significant $[F(2,34)=14.95, p<.001]$, indicating that errors, like RT, generally declined with SOA, the main effect of repetition did not gain significance $[F(1,17)=2.53, p=$ .13]. Most importantly, the SOA $\times$ repetition interaction apparent for RT was also apparent for errors $[F(2,34)=$
$10.07, p<.001]$. Planned comparisons identified as significant both the facilitative effect at the $150-\mathrm{msec}$ SOA and the inhibitory effect at the 750-msec SOA $(p<.01$ for both comparisons). No significant difference between repeat and change trials was apparent at the $450-\mathrm{msec}$ SOA $(p=.53)$.

As discussed above, because the judgment required of listeners (rise time) is independent of any location relation between cue and target, these results appear to provide quite strong evidence that location cues differentially influence perceptual sensitivity to targets in cued and uncued locations, and that this is the primary cause of facilitative and inhibitory effects. That both accuracy and RT measures of performance agree in spite of the relatively high error rates serves to reinforce this interpretation.

\section{Frequency Condition}

Statistical examination of the RT data in the frequency condition revealed a significant main effect of SOA $[F(2,34)=12.18, p<.01]$, but not of repetition $(F<1)$. The SOA $\times$ repetition interaction $[F(2,34)=8.69, p<$ $.01]$ resulted because a significant facilitative effect at $150 \mathrm{msec}$ reversed to a significant inhibitory effect at the 750-msec SOA ( $p<.02$ for both comparisons).

Although the mean error rates for repeat and change trials did not differ $(F<1)$, error rates did vary significantly as a function of SOA $[F(2,34)=10.62, p<.001]$, with most accurate and fastest performance at the longest SOA. The SOA $\times$ repetition interaction $[F(2,34)=$ $6.40, p<.01]$ was entirely consistent with that apparent for the RT analysis, in that a significant facilitative effect was apparent at the 150-msec SOA and a significant inhibitory effect was apparent at the 750-msec SOA $(p<.04$ for both comparisons). The significant facilitative and inhibitory effects apparent for both accuracy and RT measures of performance of a task independent of the cuetarget relation provide strong evidence that frequency cuing effects result because of changes in perceptual sensitivity and not because of response biases.

\section{Comparison of Performance for Location and Frequency Conditions}

Separate three-way mixed ANOVAs including one between-subjects factor (task: location, frequency) and two within-subjects factors (repetition and SOA) were

Table 1

Response Times (RT), Percent Errors (\%E), and Standard Errors (SE) as a Function of Condition, Repetition, and Stimulus Onset Asynchrony (SOA)

\begin{tabular}{|c|c|c|c|c|c|c|c|c|c|c|c|c|c|}
\hline \multirow[b]{4}{*}{ Condition } & \multirow[b]{4}{*}{ Repetition } & \multicolumn{12}{|c|}{ SOA } \\
\hline & & \multicolumn{4}{|c|}{$150 \mathrm{msec}$} & \multicolumn{4}{|c|}{$450 \mathrm{msec}$} & \multicolumn{4}{|c|}{$750 \mathrm{msec}$} \\
\hline & & \multicolumn{2}{|c|}{ RT } & \multicolumn{2}{|c|}{$\% \mathrm{E}$} & \multicolumn{2}{|c|}{ RT } & \multicolumn{2}{|c|}{$\% \mathrm{E}$} & \multicolumn{2}{|c|}{ RT } & \multicolumn{2}{|c|}{$\% \mathrm{E}$} \\
\hline & & $M$ & $S E$ & $M$ & $S E$ & $M$ & $S E$ & $M$ & $S E$ & $M$ & $S E$ & $M$ & $S E$ \\
\hline \multirow[t]{2}{*}{ Location } & Repeat & 704 & 49.51 & 28.47 & 1.06 & 658 & 39.86 & 23.37 & 1.54 & 629 & 34.50 & 23.37 & 1.36 \\
\hline & Change & 732 & 46.04 & 34.72 & 1.26 & 633 & 33.51 & 24.42 & 1.55 & 603 & 26.75 & 21.06 & 1.39 \\
\hline \multirow[t]{2}{*}{ Frequency } & Repeat & 756 & 38.38 & 27.00 & 1.46 & 722 & 39.14 & 23.60 & 1.62 & 707 & 35.10 & 24.53 & 2.17 \\
\hline & Change & 804 & 43.64 & 31.48 & 1.75 & 715 & 41.19 & 25.00 & 2.11 & 681 & 32.95 & 20.71 & 1.82 \\
\hline
\end{tabular}


performed using RTs and percent errors as dependent measures. These analyses indicated no significant differences in the performance in the two conditions. More specifically, the analysis of RTs revealed a significant main effect of SOA $[F(2,68)=26.91, p<.001]$ and a significant interaction between SOA and repetition $[F(2,68)=$ $16.60, p<.001]$. The interaction resulted, of course, because for both conditions a facilitative effect was apparent at the $150-\mathrm{msec}$ SOA and an inhibitory effect was apparent at the $750-\mathrm{msec}$ SOA. None of the other effects approached significance ( $p>.18$ in all cases).

Analysis of the error data revealed a significant main effect of $\operatorname{SOA}[F(2,68)=24.78, p<.001]$ and significant SOA $\times$ repetition interaction $[F(2,68)=16.60, p<.001]$. As was apparent for the RT data, for both conditions a facilitative effect at the $150-\mathrm{msec}$ SOA reversed to an inhibitory effect at the $750-\mathrm{msec}$ SOA. None of the other effects approached significance ( $p>.14$ in all cases).

\section{CONCLUDING COMMENTS}

As discussed above, performance of the detection, localization, and frequency identification judgments that have been used previously in investigations of auditory IOR may be affected by response biases. This is an important issue because it speaks directly to the potential theoretical interpretations of the influence of auditory cues on performance. Specifically, if listeners adopt a bias to respond more quickly in some conditions than in others, and if the direction of this bias depends on SOA, then both facilitative and inhibitory effects of auditory cues on RT could be produced, and neither would reflect the attentional operations that most investigators have suggested are responsible for these effects. In the present study, we used a rise time judgment that was independent of the cue-target relation in order to determine whether previous evidence of auditory IOR might have been the product of such response biases. The fact that facilitative and inhibitory effects were obtained when both the location and the frequency relation between cue and target were manipulated suggests that this is unlikely and that the effects more likely arise because of changes in perceptual sensitivity as a function of the temporal and spatial or spectral relations between cue and target. Moreover, the near perfect consistency of the accuracy and RT evidence not only supports this interpretation but serves also to establish that the results are not due to simple speed-accuracy tradeoffs.

One important issue with respect to developing a theoretical account of visual IOR has been the role of the eye movement system. In their review of the evidence, Rafal and Henik (1994) suggested that oculomotor programming at the level of the superior colliculi is important in determining visual IOR (see also Rafal, Egly, \& Rhodes, 1994). With regard to the effect of eye movements and occulomotor programming on auditory IOR, it appears clear that because both cue and target were presented from the same location, the frequency-based version at least is independent of these considerations. However, since eye movements were not monitored in our study, it is not possible for us to address directly the possible role of eye movements in determining locationbased auditory IOR. Informal observations of listener behavior during practice sessions indicated that most attempted to limit visual processing either by closing their eyes or by looking down to the keyboard so as to limit distraction by performance feedback messages on the computer screen.

These observations, which might be interpreted as suggesting that location-based IOR is not dependent on eye movements toward possible target locations, is at odds with recent evidence that auditory cues engender an inhibitory effect only when eye movements are made first toward and then away from the location of the cue (Reuter-Lorenz \& Rosenquist, 1996). ${ }^{2}$ A potential cause for concern with this study is that in only one of the four experiments reported by Reuter-Lorenz and Rosenquist was it possible that an auditory cue could be followed by an auditory target, and even then such within-modality trials were intermixed with an equal number of mixedmodality trials in which an auditory cue was followed by a visual target. Given that there appears to be a markedly attenuated effect of spatial cues for mixed-modality trials relative to similar within-modality trials (e.g., Mondor \& Amirault, 1998; Spence \& Driver, 1997), the use of such trials would be expected to significantly reduce the likelihood of identifying any effect of auditory cues, inhibitory or otherwise. This interpretation is supported by the results of a study reported by Schmidt (1996), which demonstrated location-based IOR when both cue and target were acoustic even though listeners were required to keep their eyes closed and to refrain from making any eye movements. It would appear prudent, therefore, to view the results reported by Reuter-Lorenz and Rosenquist (1996) as suggesting that eye movements may be necessary to generate an inhibitory effect of auditory spatial cues on visual target detection. Irrespective of this issue, however, the results of the present study indicate that both auditory location and frequency cues affect subsequent target judgments through a modulation of perceptual sensitivity.

Location and frequency cues may affect any one of a number of primitive or advanced perceptual processes involved in processing subsequent targets. Consider, for example, the model proposed by Houghton and Tipper (1994), which provides an explicit account of the operation of visual selective attention. These authors suggest that both facilitative and inhibitory effects of visual spatial cues arise because of processes involved in selecting and transferring the target perceptual representation to higher level processes such as response selection. Perceptual representations that match a prespecified description or template are facilitated, whereas perceptual representations that do not match the template are inhibited from more complex cognitive processing. The important point here is that such a matching mechanism can explain both 
facilitative and inhibitory effects and that these arise neither because of response biases nor because of changes in the sensitivity of low-level perceptual processes.

A complete theoretical account of the effects of auditory cues remains to be developed. However, the present study has demonstrated facilitative and inhibitory effects of both location and frequency cues on the speed and accuracy of making a rise time judgment. Given that the judgment required of listeners is independent of the cuetarget relation and the consistency of the RT and error results, it appears that facilitative and inhibitory effects of auditory cues arise primarily because of modulations in perceptual sensitivity as a function of the time period between cue and target.

\section{REFERENCES}

BASHINSKI, H. S., \& BaChaRACH, V. R. (1980). Enhancement of perceptual sensitivity as the result of selectively attending to spatial locations. Perception \& Psychophysics, 28, 241-248.

Bernstein, I. H., Chue, P. K., Briggs, P., \& Schurman, D. L. (1973). Stimulus intensity and foreperiod effects in intersensory facilitation. Quarterly Journal of Experimental Psychology, 25, 171-181.

Bregman, A. S., ACHIM, A., \& Ahad, P. A. (1992). The Maple software system [Computer program]. McGill University, Department of Psychology.

CreElman, C. D. (1959). Detection of signals of uncertain frequency. Journal of the Acoustical Society of America, 32, 805-810.

DowNING, C. J. (1988). Expectancy and visual-spatial attention: Effects on perceptual quality. Journal of Experimental Psychology: Human Perception \& Performance, 14, 188-202.

Gescheider, G. A. (1985). Psychophysics: Method, theory, and application. Hillsdale, NJ: Erlbaum.

GREEN, D. M. (1961). Detection of auditory sinusoids of uncertain frequency. Journal of the Acoustical Society of America, 33, 897-903.

GREENBERG, G. Z., \& LARKIN, W. D. (1968). Frequency-response characteristics of auditory observers detecting signals of a single frequency in noise: The probe-signal method. Journal of the Acoustical Society of America, 44, 1513-1523.

HARVEY, N. (1980). Non-informative effects of stimuli functioning as cues. Quarterly Journal of Experimental Psychology, 32, 413-425.

Hawkins, H. L., Hillyard, S. A., Luck, S. J., Mouloua, M., DownING, C. J., \& WoodWARD, D. P. (1990). Visual attention modulates signal detectability. Journal of Experimental Psychology: Human Perception \& Performance, 16, 802-811.

HENKE, W. L. (1992). An interactive dialogue language for time signal processing [Computer program]. Cambridge, MA: MIT Research Laboratory of Electronics.

Houghton, G., \& Tipper, S. P. (1994). A model of inhibitory mechanisms in selective attention. In D. Dagenbach \& T. H. Carr (Eds.), Inhibitory processes in attention, memory, and language (pp. 52-112). San Diego: Academic Press.

Kinchla, R. A. (1992). Attention. Annual Review of Psychology, 43, $711-742$.

KLEIN, R. M., \& HANSEN, E. (1990). Chronometric analysis of apparent spotlight failure in endogenous visual orienting. Journal of Experimental Psychology: Human Perception \& Performance, 16, 790-801.

KLEIN, R. M., \& TAYLOR, T. L. (1994). Categories of cognitive inhibition with reference to attention. In D. Dagenbach \& T. H. Carr (Eds.), Inhibitory processes in attention, memory, and language (pp. 113150). San Diego: Academic Press.

Lupiáñez, J., Milán, E. G., Tornay, F. J., Madrid, E., \& Tudela, P. (1997). Does IOR occur in discrimination tasks?: Yes, it does, but later. Perception \& Psychophysics, 59, 1241-1254.

MAYLOR, A. M., \& HOCKEY, R, (1985). Inhibitory component of externally controlled covert orienting in space. Journal of Experimental Psychology: Human Perception \& Performance, 11, 777-787.
Mondor, T. A., \& AMIRAuLT, K. J. (1998). Effect of same- and differentmodality spatial cues on auditory and visual target identification. Journal of Experimental Psychology: Human Perception \& Performance, 24, 745-755.

Mondor, T. A., BreAu, L. M., \& Milliken, B. (1998). Inhibitory processes in auditory selective attention: Evidence of location-based and frequency-based inhibition of return. Perception \& Psychophysics, 60, 296-302.

Mondor, T. A., \& Bregman, A. S. (1994). Allocating attention to frequency regions, Perception \& Psychophysics, 56, 268-276.

MONDOR, T. A., \& BRYDEN, M. P. (1992). Orienting of auditory spatial attention: Effects of a lateralized tone cue. Neuropsychologia, $\mathbf{3 0}$, 743-752.

Mondor, T. A., \& ZATORRE, R. J. (1995). Shifting and focusing auditory spatial attention. Journal of Experimental Psychology: Human Perception \& Performance, 21, 387-409.

Mondor, T. A., ZATORRE, R. J., \& TERrio, N. A. (1998). Constraints on the selection of auditory information. Journal of Experimental Psychology: Human Perception \& Performance, 24, 1-14.

Moray, N. (1959). Attention in dichotic listening: Affective cues and the influence of instructions. Quarterly Journal of Experimental Psychology, 12, 214-220.

Moray, N. (1974). A data base for theories of selective listening. In P. M. A. Rabbitt \& S. Dornic (Eds.), Attention and performance $V$ (pp. 119-135). New York: Academic Press.

Mǘler, H. J., \& FindLAY, J. M. (1987). Sensitivity and criterion effects in the spatial cuing of visual attention. Perception \& Psychophysics, 42, 383-399.

MülLER, H. J., \& HuMPHREYs, G. W. (1991). Luminance-increment detection: Capacity-limited or not? Journal of Experimental Psychology: Human Perception \& Performance, 17, 107-124.

NICKERSON, R. S. (1973). Intersensory facilitation of reaction time: Energy summation or preparation enhancement? Psychological Review, 80, 489-509.

PACHELla, R. G. (1974). The interpretation of reaction time in informationprocessing research. In B. Kantowitz (Ed.), Human information processing: Tutorials in performance and cognition (pp. 41-82). Hillsdale, NJ: Erlbaum.

PoSNER, M. I., \& CoHEN, Y. (1984). Components of visual orienting. In H. Bouma \& D. G. Bouwhuis (Eds.), Attention and performance X: Control of language processes (pp. 531-555). Hillsdale, NJ: Erlbaum.

PRATT, J. (1995). Inhibition of return in a discrimination task. Psychonomic Bulletin \& Review, 2, 117-120.

Pratt, J., Kingstone, A., \& KHOE, W. (1997). Inhibition of return in location- and identity-based choice decision tasks. Perception \& Psychophysics, 59, 964-971.

Rafal, R. D., Calabressi, P. A., Brennan, C. W., \& Sciolto, T. K. (1989). Saccade preparation inhibits reorienting to recently attended locations. Journal of Experimental Psychology: Human Perception \& Performance, 15, 673-685.

RAFAL, R. [D.], EGLY, R. \& RHODES, D. (1994). Effects of inhibition of return on voluntary and visually guided saccades. Canadian Journal of Experimental Psychology, 48, 284-300.

RAFAL, R. [D.], \& HeNIK, A. (1994). The neurology of inhibition: Integrating controlled and automatic processes. In D. Dagenbach \& T. H. Carr (Eds.), Inhibitory processes in attention, memory, and language (pp. 1-51). San Diego: Academic Press.

Reuter-Lorenz, P. A., JhA, A. P. [D.], \& Rosenquist, J. N. (1996). What is inhibited in inhibition of return? Journal of Experimental Psychology: Human Perception \& Performance, 22, 367-378.

Reuter-LoRenZ, P. A., \& Rosenquist, J. N. (1996). Auditory cues and inhibition of return: The importance of oculomotor activation. Experimental Brain Research, 112, 119-126.

RHODES, G. (1987). Auditory attention and the representation of spatial information. Perception \& Psychophysics, 42, 1-14.

SANDERS, A. F. (1975). The foreperiod effect revisited. Quarterly Journal of Experimental Psychology, 27, 591-598.

Scharf, B., Quigley, S., Aokı, C., Peachey, N., \& Reeves, A. (1987). Focused auditory attention and frequency sensitivity. Perception \& Psychophysics, 42, 215-223. 
SCHLAUCH, R. S., \& HAFTER, E. R. (1991). Listening bandwidths and frequency uncertainty in pure-tone signal detection. Journal of the Acoustical Society of America, 90, 1332-1339.

SCHMIDT, W. C. (1996). Inhibition of return without visual input. Neuropsychologia, 34, 943-952.

SHAW, M. L. (1978). A capacity allocation model for reaction time. Journal of Experimental Psychology: Human Perception \& Performance, 4, 586-598.

SHAW, M. L. (1984). Division of attention among spatial locations: A fundamental difference between detection of letters and detection of luminance increments. In H. Bouma \& D. G. Bouwhuis (Eds.), Attention and performance $X$ : Control of language processes (pp. 109121). Hillsdale, NJ: Erlbaum.

SPENCE, C. J., \& DRIVER, J. (1994). Covert spatial orienting in audition: Exogenous and endogenous mechanisms. Journal of Experimental Psychology: Human Perception \& Performance, 20, 555-574.

SPENCE, C. [J.], \& DrIver, J. (1997). Audiovisual links in exogenous covert spatial orienting. Perception \& Psychophysics, 59, 1-22.

Tipper, S. P., Weaver, B., Jerreat, L. M., \& Burak, A. L. (1994). Object-based and environment-based inhibition of return of visual attention. Journal of Experimental Psychology: Human Perception \& Performance, 20, 478-499.
Treisman, A. M. (1960). Contextual cues in selective listening. Quarterly Journal of Experimental Psychology, 12, 242-248.

Treisman, A. M. (1969). Strategies and models of selective attention. Psychological Review, 76, 282-299.

\section{NOTES}

1. "Perceptual sensitivity," as used in the present context (and throughout the paper) should not be interpreted strictly as indicative of a physiological effect at a peripheral level of the auditory system (see also Hawkins et al., 1990, who made a similar point). Rather the term is used generally to represent a class of possible effects, separate from response biases, in any one of the primitive or advanced perceptual processes involved in performing a task.

2. We thank an anonymous reviewer for bringing this paper to our attention.

(Manuscript received September 26, 1997; revision accepted for publication March 4, 1998.) 